\title{
The Indication for Cervical Cerclage and Pregnancy Outcome in a Teritiary Hospital in South-South Nigeria: A Five Year Review
}

\author{
Dr. Dennis Allagoa, \\ BMedsc (Pharm) MBBS, FWACS, FMAS, DMAS, CERT ART, Dip HMS, \\ FICS, Consultant, Obstetrician/Gynaecologist, Federal Medical Centre \\ Yenagoa, Bayelsa State, Nigeria \\ Dr. John Agbo, \\ MBBS, FWACS, Consultant Obstetrician and Gynaecologist, \\ Federal Medical Centre Yenagoa, Bayelsa State, Nigeria
}

Doi:10.19044/esj.2019.v15n24p200 URL:http://dx.doi.org/10.19044/esj.2019.v15n24p200

\begin{abstract}
Background: Cervical incompetence is a major cause of second trimester miscarriage. Recurrent pregnancy loss in the second trimester is associated with significant distress. However, there should be a justifiable indication before a cerclage is inserted. There is no documentation of the indication of cervical cerclage and pregnancy outcome in Yenagoa, southsouth Nigeria. Objectives: This paper focuses on documenting the indication and obstetric outcome following cervical cerclage insertion at the Federal Medical Center Yenagoa, Bayelsa State. Methodology: A 5 year retrospective study was carried out in women who had cervical cerclage for cervical incompetence in the Federal Medical Centre, Yenagoa. The study was conducted from the $1^{\text {st }}$ of January 2014 to $31^{\text {st }}$ of December 2018. All the case files of patients who had cervical cerclage were retrieved and reviewed. Results: A total of 41 patients had cervical cerclage. The commonest indication for cervical cerclage insertion was history indicated cerclage $59.4 \%$. This was followed by ultrasound indicated cerclage $28.1 \%$ and rescue cerclage accounting for $12.5 \%$. All patients employed McDonald's method of cervical cerclage. The position of the knot was in 120 ' clock position in $53.1 \%$ of the patients and in the 60 'clock position for $46.9 \%$ of the patients. The success rate following insertion of cerclage was $79.3 \%$. The mode of deliveries was vaginal in $90.6 \%$ of the patients and $9.4 \%$ had caesarean section. Conclusion: There may be concern about the diagnosis of cervical incompetence. However, findings from this study clearly showed that the application of cervical cerclage is associated with good obstetric outcome.
\end{abstract}


Keywords: Indication, Cerclage, incompetence

\section{Introduction}

Cervical incompetence is the inability of the cervix to retain the pregnancy until term because of a structural or functional defect. It is an important cause of recurrent mid trimester pregnancy loss and preterm delivery (Sandhu et al., 2008). The causes of cervical incompetence may be congenital or acquired (Sandhu et al., 2008; Kwawukume et al., 2015). Congenital causes could be from uterine anomalies like biconuate uterus, uterine didelphy, septate uterus, low cervical collagen content, and in-utero exposure to diethylstilbestrol (Sandhu et al., 2008; Kwawukume et al., 2015). The acquired causes are traumatic and they are regarded as the commonest cause of cervical incompetence in our societies (Kwawukume et al., 2015). This is as a result of excessive and forceful dilatation of the cervix for termination of pregnancy, unlike in developed societies where it may be largely due to trauma to the cervix following cervical amputation and deep cone biopsy (Kwawukume et al., 2015; Edwards, 2007).

The indication for insertion of cervical cerclage may be sub-divided into; history, ultrasound, and rescue (Royal College of Obstetricians and Gynaecologists Green top guidelines, 2005). In the case of history indicated cerclage insertion, the patient had an obstetric or gynaecological history that is keeping with the need to insert a cerclage (RCOG Green top guidelines, 2005). It is recommended for women with three or more preterm or second trimester pregnancy loss (RCOG Green top guidelines, 2005). Other school of thoughts recommended insertion of history indicated cerclage following one previous midtrimester pregnancy loss (American College of Obstetrics and Gynaecology, 2014). Ultrasound has actually become a veritable tool in the diagnosis and follow-up of patients with cervical incompetence (Ikimalo et al., 2012). This is done for women who have not undergo history indicated cerclage but are on follow-up with serial sonographic surveillance (RCOG Green top guidelines, 2005). Studies have shown that unnecessary history indicated cerclage procedures can be avoided in more than $50 \%$ of patients when follow up with serial sonographic surveillance is done (Brown et al., 2011; Berghella et al., 2011).Ultrasound indicated cerclage is inserted when there is evidence of cervical shortening on ultrasound or a cervical length of less than $2.5 \mathrm{~cm}$ in the second trimester (Arisoy \& Yayla, 2012). Some patients may benefit from rescue cerclage when they present clinical evidence of membranes bulging into the vaginal (RCOG Green top guidelines, 2005).

The definitive management of cervical incompetence involves strengthening of the cervix with suture materials as enunciated by Shirodkar in 1955 and modified by McDonald in 1965 (Kwawukume et al., 2015; Edwards, 2007; 
RCOG green top guidelines, 2005; ACOG, 2014). Both methods have similar outcome; however, the McDonald is simpler (Alabi-Isama et al., 2012).

The use of cervical cerclage has significantly improved pregnancy outcome in the Federal Medical Center Yenagoa. There is no documentation of the indication and pregnancy outcome following the application of cervical cerclage in the institution. This study documented the indications of cervical cerclage and pregnancy outcome following the application of cervical cerclage.

\section{Methodology}

This study was a retrospective study that was conducted from the $1^{\text {st }}$ of January 2014 to $31^{\text {st }}$ of December 2018 in the Federal Medical Centre Yenagoa. A total of 41 women had cervical cerclage for cervical incompetence during the period the study was conducted. Their case files were retrieved from the records Department of the Hospital and were analyzed.

The following information was obtained from each patient's case file: the patient's socio-demographic data, the gestational age at which cerclage was inserted, and the indication for cerclage insertion. Other information obtained included: the method of cerclage inserted, the position of the knot, whether the patient had post-operative antibiotics or tocolytics. Complications following the procedure include the duration of hospital stay, the gestational age at which the knot was removed, and the mode of delivery.

\section{Results}

A total of 41 women had cervical cerclage inserted for cervical incompetence during the 5 year period the review was conducted, and only 32 of the case files had required information for the study properly documented. A total of 16106 pregnancies were managed at the antenatal clinic from the $1^{\text {st }}$ of January 2014 to $31^{\text {st }}$ of December 2018. Therefore, the cerclage rate was $0.25 \%$. The age range of the patients was $29-42$ years. A total of 19 patients $(59.4 \%)$ had history indicated cerclage and 9 of the patients $(28.1 \%)$ had ultrasound indicated cerclage. Rescue cerclage was inserted in 4 of the patients (12.5\%). All the patients employed McDonald's method of cerclage insertion. The position of the knot was in 6 o'clock in 15 of the women $(46.9 \%)$ and 17 of the women $(53.1 \%)$ had the knot in 12 o'clock position. Post-operative antibiotics were administered in 30 of the patients (93.8), while 2 of the patients $(6.2 \%)$ had no post-operative antibiotics administered. A total of 28 of the patients $(87.5 \%)$ received post-operative tocolytics and 4 of the patients $(12.5 \%)$ did not receive post-operative tocolytics. The range of hospital stay following cerclage insertion was between 2 to 18 days. Three (3) of the patients had complications following cerclage insertion. Most of the patients had their cerclage removed at 37 weeks of gestation. The mode of deliveries 
was vaginal in 29 of the women $(90.6 \%)$ and 3 of the women $(9.4 \%)$ had caesarean section as their mode of delivery.

Table 1. Age of patients

\begin{tabular}{|l|l|l|}
\hline Age $(\mathrm{yrs})$ & Number & Percentage (\%) \\
\hline $20-24$ & 1 & 3.1 \\
$25-29$ & 9 & 28.1 \\
$30-34$ & 15 & 46.9 \\
$35-39$ & 5 & 15.6 \\
$40-45$ & 2 & 6.3 \\
\hline
\end{tabular}

Table 2. Indication for cerclage insertion

\begin{tabular}{|c|c|c|}
\hline Indication & Number & Percentage (\%) \\
\hline History & 19 & 59.4 \\
Ultrasound & 9 & 28.1 \\
Rescue & 4 & 12.5 \\
\hline
\end{tabular}

Table 3. Gestational age at cerclage insertion

\begin{tabular}{|c|c|c|}
\hline Gestational age (weeks) & Number & Percentage (\%) \\
\hline$<14$ & 5 & 15.6 \\
$14-16$ & 17 & 53.1 \\
$>16$ & 10 & 31.3 \\
\hline
\end{tabular}

Table 4. Method of cerclage

\begin{tabular}{|c|c|c|}
\hline Method & Number & Percentage (\%) \\
\hline McDonald & 32 & 100 \\
Shirodkar & 0 & 0 \\
\hline
\end{tabular}

Table 5. Position of knot

\begin{tabular}{|c|c|c|}
\hline Position & Number & Percentage (\%) \\
\hline 6 0' clock & 15 & 46.9 \\
120'clock & 17 & 53.1 \\
\hline
\end{tabular}

Table 6. Mode of delivery

\begin{tabular}{|c|c|c|}
\hline Mode & Number & Percentage (\%) \\
\hline Vaginal & 29 & 90.6 \\
Caesarean section & 3 & 9.4 \\
\hline
\end{tabular}

\section{Discussion}

Cervical cerclage insertion is a well known procedure that is associated with significant improvement in fetal outcome. There should be a clear indication before cerclage is inserted. Therefore, this will ensure that only patients with incompetent cervix benefit from the procedure, and this reduces the rate of unnecessary cerclage insertion. Cerclage may be inserted based on various indications which may include: history, ultrasound, and rescue cerclage (RCOG green top guidelines, 2005).

This study showed that most women had history indicated cerclage (19) $59.4 \%$. This was followed by ultrasound indicated cerclage (9) $28.1 \%$ and 
rescue cerclage (4) $12.5 \%$. In a similar study in Abuja North Central Nigeria, (75) $78.1 \%$ of the women had history indicated cerclage, (21) $21.9 \%$ had rescue cerclage, while none had ultrasound indicated cerclage (Adewole et al., 2018). In other studies in Irua, Edo State South-South Nigeria and Nairobi Kenya, most of the patients had history indicated cerclage (Okusanya \& Isabu, 2015; Kaura et al., 2013). The high number of patients that had history indicated cerclage in these studies may be due to the fact that ultrasound scan was used for few patients in the studies. It has been shown that sonographic surveillance may reduce unnecessary history indicated cerclage by $50 \%$ (Brown et al., 2011; Berghella et al., 2011).

The major finding in our study was the success rate of $79.3 \%$ following cervical cerclage. Most studies have similar success rate (Ikimalo et al., 2012; Adewole et al., 2018; Okusanya \& Isabu, 2015). This is a major pointer to the effectiveness of cervical cerclage in preventing midtrimester pregnancy loss and preterm labour. The indication of cerclage insertion also determines the success rate of cervical cerclage (Khan et al., 2012; Liddiard et al., 2011). Studies have shown that success rate is lowest following rescue cerclage insertion (Khan et al., 2012; Liddiard et al., 2011). However, in a study conducted in Israel, success rate was similar in respective of the indication for cerclage insertion (Gluck et al., 2017).

The study showed that (17) $53.1 \%$ of the women had cerclage inserted between 14-16 weeks of gestation. This may be due to the fact that most of the women had history indicated cerclage which is generally inserted between 1416 weeks of gestational age, so that natural selection of non-viable pregnancy can take place (Umashe, 2013). The findings in this study aim to keep up with what was obtained in other studies (Adewole et al., 2018; Wafi et al., 2018). The study also showed that (5) $15.6 \%$ had cerclage inserted at less than 14 weeks and (10) $31.3 \%$ had cerclage inserted at greater than 16 weeks.

McDonald method of cerclage insertion was employed for all the patients in this study. This was the commonest method of cervical cerclage in most studies (Ikimalo et al., 2012; Adewole et al., 2018; Okusanya \& Isabu, 2018). However, in another study in Aba, South East Nigeria, 65\% of the women employed Shirodkar method and 35\% employed McDonald method (FeyiWaboso \& Umezurike, 2005). The fetal salvage rate in the study justified the fact that both methods have similar outcome (Ikimalo et al., 2012; Alabi-Isabu, 2015). However, McDonald method is simpler and does not require anaesthesia for removal.

The position of the knot was at the 12 o'clock position in (17) $53.1 \%$ of the patients and in the 6 o'clock position in (15) $46.9 \%$ of the patients. Studies have showed similar pregnancy outcome irrespective of the position of the knot (Ikimalo et al., 2012; Atia et al., 2018). 
In conclusion, this study has certain limitation and issues that may attract criticism. First, there has not been an agreed protocol on the diagnosis of cervical incompetence. Second, the number of patients in the study was small. Third, ten (10) of the case files did not contain adequate information for the study. Based on the above limitations notwithstanding, the study clearly highlights that pregnancies were actually saved following the insertion of cervical cerclage. Hence, we recommend the use of cervical cerclage in improving the fetal salvage rate and reducing the recurrent midtrimester pregnancy loss.

\section{References:}

1. American College of Obstetricians and Gynaecologists (2014). Cerclage for the management of cervical insufficiency 8:142.

2. Adewole, N., Isah, AD., \& Okochi, O. (2018). A five year survey of cervical cerclage at a Nigerian Tertiary Hospital. J Gynaecol Reprod Med; 2(1): 1-5.

3. Alabi-Isama, L., Sykes, L., Chandiramani, M., Patel, S., Rai, R., et al. (2012). Time interval from removal of cerclage to onset of spontaneous labour. Euro J Obstet Gynaecol \& Reprod Bio; 165:235238.

4. Arisoy, R. \& Yayla, M. (2012). Transvaginal sonographic evaluation of the cervix in asymptomatic singleton pregnancy and management options in short cervix. J of Pregnancy; 1-10.

5. Atia, H., Ellaithy, M., Altraigey, A., \& Ibrahim, H. (2018). Knot positioning during McDonalds cervical cerclage, does it make a difference? A cohort study. J Matern Fetal Neonatal Med; 15:1-7.

6. Bennett, P. (2007). Preterm labour. In: Edwards DK. (Ed). Dewhurst's textbook of Obstetrics and Gynaecology, $8^{\text {th }}$ edition London: Blackwell Publishing; 356-373

7. Berghella, V., Rafael, TJ., Szychowski, JM., Rust, OA., \& Owen, J. (2011). Cerclage for short cervix on ultrasonography in women with singleton gestations and previous preterm birth: a meta-analysis. Obstet Gynaecol; 117:663-71.

8. Brown, JA., Pearson, AW., Veillon, EW., Rust, OA., Chauhan, SP., Magann, EF., et al. (2011). History or ultrasound based cerclage placement and adverse perinatal outcomes. J Reprod Med; 56:385-92.

9. Feyi-Waboso, PA. \& Umezurike, CC. (2005). Management of cervical incompetence in Aba, south-eastern Nigeria. Niger J Med; 14(4):4004.

10. Gluck, O., Mizrachi, Y., Ginath, S., Bar, J., \& Sagiv, R. (2017). Obstetric outcomes of emergency compared to elective cervical cerclage. J Matern Fetal Neonatal Med; 30(14):1650-165416. 
11. Ikimalo, J., Izuchukwu, KE., \& Inimgba, N. (2012). Pregnancy outcome after cerclage for cervical incompetence at the University of Port Harcourt teaching hospital, Port Harcourt. Afri J Reprod Health; 16(3):180-184.

12. Karau, PB., Mutwiri, MG., Ogeng'o, JA., Karau, GM. (2013). Use of cervical cerclage as a treatment option for cervical incompetence: Patients characteristics, presentation and management over a 9 year period in a Kenyan center. Afr J Reprod Health; 17(1):169-173.

13. Khan, MJ., Ali, G., Al Tajir, G., \& Suleiman, H. (2012). Evaluation of outcomes associated with placement of elective, urgent and emergency cerclage. J Obstet Gynae; 62(6):660-664.

14. Liddiard, A., Bhattacharya, S., \& Crichton, L. (2011). Elective and emergency cervical cerclage and immediate pregnancy outcomes: a retrospective observational study. J R Soc Sh Rep; 2(11):91-97.

15. Nkyekyer, K. (2015). Cervical incompetence. In: Kwawukume EY, Ekele BA, Danso KA and Emuveyan EE (Eds). Comprehensive Obstetrics in the Tropics $2^{\text {nd }}$ Edition. Accra: Assemblies of God printing press limited; 415-425.

16. Okusanya, BA. \& Isabu, PA. (2015). Outcome of pregnancy with history-indicated cervical cerclage insertion in a low-resource setting. J Matern Fetal Neonatal Med; 28(3)284-287.

17. Royal College of Obstetricians and Gynaecologist (2011). Cervical cerclage (Green-Top guidelines) 60: 1-21.

18. Sandhu, KS., Keeler, S., \& Seubert, DE. (2008). Cervical insufficiency. In: Progress in Obstetrics and Gynaecology. John Studd, Seang Lin Tan, Frank Chervenak (Eds). London, Elsevier Publishers; 175-18.

19. Umashe, RK. (2013). Cervical cerclage outcome. Afri J Reprod Health; 17:223-235.

20. Wafi, A., Faron, G., Parra, J., \& Gucciardo, L. (2018). Influence of cervical cerclage interventions upon the incidence of neonatal death: a retrospective study comparing prophylactic versus rescue cerclages. Facts Views Vis Obgyn; 10(1):29-36. 